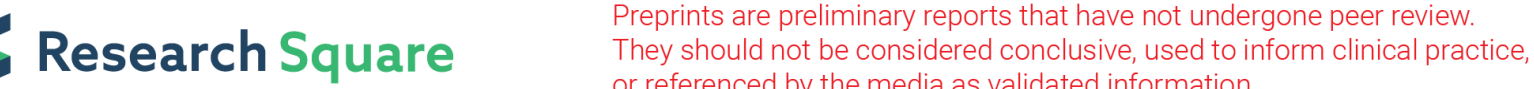 or referenced by the media as validated information.
}

\section{Fine Mapping and Candidate Gene Analysis of the Up Locus Determining Fruit Orientation in Pepper (Capsicum spp.)}

\section{Fang $\mathrm{Hu}$}

South China Agricultural University https://orcid.org/0000-0003-0562-2602

\section{Jiaowen Cheng}

South China Agricultural University

Jichi Dong

South China Agricultural University

Jian Zhong

South China Agricultural University

\section{Ziyan Zhou}

South China Agricultural University

Kailin Hu ( $D$ hukailin@scau.edu.cn )

South China Agricultural University

\section{Research Article}

Keywords: Pepper, Fruit orientation, Fine-mapping, Candidate gene analysis

Posted Date: February 24th, 2021

DOI: https://doi.org/10.21203/rs.3.rs-235544/v1

License: (c) (i) This work is licensed under a Creative Commons Attribution 4.0 International License. Read Full License 


\section{Abstract}

Fruit orientation is an important horticultural and domesticated trait, which is controlled by a single semi-dominant gene (up) in pepper. However, the gene underlying up locus has not yet been identified. In this study, the previously detected major QTL UP12.1 was firstly verified using an intraspecific backcross population $(n=225)$ stem from the cross of BB3 (C. annuum) and its wild relative Chiltepin (C. annuum var. glabriusculum) using BB3 as the recurrent parent. Then, a large $\mathrm{BC}_{1} \mathrm{~F}_{2}$ population $(\mathrm{n}=1827)$ was used for recombinant screening to delimit the up locus into an interval with $\sim 169.51 \mathrm{~kb}$ in length. Sequence comparison and expression analysis suggested that Capana12g000958, encoding a developmentally regulated G-protein 2, was the most likely candidate gene for up. The findings of this study will form a basis for gene isolation and reveal of genetic mechanism underlying the fruit orientation domestication in pepper.

\section{Key Message}

The up locus determining fruit orientation in pepper was fine mapped into a region with a physical length of $\sim 169.51$ kb on chromosome P12. Capana 12g000958, encoding a developmentally regulated G-protein 2, was proposed as the strongest candidate via sequence comparison and expression analysis.

\section{Introduction}

Plant organ orientation is governed by antagonistic interactions of the ubiquitous gravitropic mechanism and auxindependent antigravitropic offset mechanism (Roychoudhry et al. 2013). It is a crucial important constituent trait determining the morphogenesis of higher plants. The dynamic control model of growth direction has been well established in roots and shoots. In this model, the TIR1/AFB-Aux/IAA-ARF-dependent auxin signaling pathway plays a dominant role in gravity sensing by regulating the magnitude of the antigravitropic offset component (Roychoudhry et al. 2013). However, there is comparatively little attention has been paid to the genetic regulation of fruit/pedicel orientation, which is fundamentally determined by the lateral organ pedicel's adaxial-abaxial polar growth in flowering plants (Venglat et al. 2002).

In Arabidopsis, several molecular regulators that govern alterations in pedicel orientation have been identified. They include the BREVIPEDICELLUS (KNAT1/BP) (Douglas et al. 2002; Venglat et al. 2002), ASYMMETRIC LEAVES1/2 (AS1/2) (Xu et al. 2003), CORYMBOSA1 (CRM1/BIG) (Yamaguchi et al. 2007), KNOTTED-like2/6 (KNAT2/6) (Ragni et al. 2008), ARABIDOPSIS THALIANA HOMEOBOX GENE1 (ATH1) (Li et al. 2012) and LEAFY (LFY) (Yamaguchi et al. 2012). The Arabidopsis brevipedicellus mutant that disrupted in the KNAT1/BP gene displays reduced pedicel lengths and downward-oriented flowers (Douglas et al. 2002; Venglat et al. 2002). KNAT1/BP negatively regulates KNAT2, KNAT6, and ATH1 to ensure that pedicels have a normal upward-pointing orientation (Ragni et al. 2008; Li et al. 2012). $A S 1$ and $A S 2$, two critical regulators of leaf polarity, can also induce pedicels to grow downward by downregulating the expression of KNAT1/BP, KNAT2, KNAT6, and ATH1 (Li et al. 2012). The CRM1/BIG, an auxin transport-related gene, and $\angle F Y$, a hypomorph allele of the meristem identity regulator, are involved in the regulation of KNAT1/BP and AS2 expression (Yamaguchi et al. 2007, 2012). In other non-model plants, NtSVP in tobacco, SIAGO7 in tomato, and CSUp in cucumber were found to participate in the developmental regulation of pedicel/fruit orientation (Wang et al. 2015; Lin et al. 2016; Sun et al. 2019).

Pepper (Capsicum spp.) belongs to the Solanaceae family and is one of the earliest domesticated crops in Central and South America with versatile applications (Cheng et al. 2016b). It is widely used in the fields of vegetable consumption, medicine (Hernández-Ortega et al. 2012), biological control (Castillo-Sánchez et al. 2012), and military 
(Reilly et al. 2001) nowadays. Fruit orientation is one of the domesticated traits in pepper (Paran and Van Der Knaap 2007). Currently, most cultivated species of pepper have transformed from the wild erect type of fruit orientation to the pendant one. This change may be associated with an increase in fruit size, better protection from sun exposure, and predation by birds (Paran and Van Der Knaap 2007). Fruit orientation is also an important horticultural trait for pepper because it influences pollination, yield, and harvesting approaches (Lee et al. 2008; Wang et al. 2014a). However, the underlying genetic mechanism of this trait remains poorly understood.

Previous genetic analyses showed that the pepper fruit's erect trait is controlled by a single recessive gene which was named up (Lippert et al. 1965; Cheng et al. 2016a). Two linked markers, namely $\mathrm{A}_{2} \mathrm{C}_{469}$ and upCAPS, were developed with a genetic distance of $1.7 \mathrm{cM}$ and $4.3 \mathrm{cM}$ from the up locus (Lee et al. 2008), respectively.

Furthermore, two major and four minor quantitative trait loci (QTLs) were detected under four different environments based on an ultra-high-density bin map. Of which, a stable and major QTL, namely FP-12.2, was identified at 199.6 $\mathrm{Mb}$ on the pepper chromosome P12 in the CM334 genome, explaining over 40\% of the phenotypic variation (Han et al. 2016). In addition, a major QTL, named Up12.1, was identified at $36.54 \varangle 41.06 \mathrm{Mb}$ on the chromosome P12 in the Zunla-1 genome based on a high-density single nucleotide polymorphism (SNP) map. There were 65 protein-coding genes were predicted within this QTL region based on the current annotation of the Zunla-1 genome (Cheng et al. 2016a).

In this study, the previous detected major QTL UP12.1 was firstly verified using an intraspecific backcross population stem from the cross of BB3 (C. annuum) and its wild relative Chiltepin ( C. annuum var. glabriusculum) using BB3 as the recurrent parent. Furthermore, a large $\mathrm{BC}_{1} \mathrm{~F}_{2}$ population was constructed and used for recombinant screening and fine mapping of the up. The candidate genes embedded in the fine mapping region were then analyzed by sequence and expression comparisons. The expression profile of a strong candidate, Capana12g000958, was elaborately examined in various tissues at different developmental stages. The findings of this study will form a basis for the gene isolation and revealing of the underlying genetic mechanism of fruit orientation domestication in pepper.

\section{Materials And Methods}

\section{Plant materials}

The pepper inbred line BB3 (C. annuum) and its wild relative Chiltepin (C. annuum var. glabriusculum) were used as the female and male parents, respectively, to construct a backcross population $\left(B C_{1} F_{1}, n=225\right)$ with $B B 3$ as the recurrent parent to verify the UP12.1 interval previously detected based on the BA3 (C. annuum) $\times$ YNXML $(C$. frutescens) $F_{2}$ population (Cheng et al. 2016a). The BB3, Chiltepin, and their $F_{1}$ and $\mathrm{BC}_{1} \mathrm{~F}_{1}$ population were grown at SCAU Main Campus Teaching \& Research Base, Guangzhou, China $\left(23^{\circ} \mathrm{N}, 113^{\circ} \mathrm{E}\right)$.

A total of $1,827 \mathrm{BC}_{1} \mathrm{~F}_{2}$ individuals were generated by artificial self-pollination with the heterozygous individuals from the $\mathrm{BC}_{1} \mathrm{~F}_{1}$ population to narrow down the up candidate interval. Fruit orientation phenotypes were evaluated with at least five flowers/fruits were recorded from stage S3 to S7 (Fig. 1) for each plant based on the ELV (E: erect, LP: lateral pendant, VP: vertical pendant) classification method as described previously (Cheng et al. 2016a).

\section{Marker genotyping}

Insertion and deletion (InDel) loci were identified based on sequence comparisons between the reference genome sequences of Zunla-1 and Chiltepin (Qin et al. 2014). Primer pairs flanking the InDel loci were designed by using 
Primer3web (version 4.1.0; http://primer3.ut.ee/). DNA was extracted from young leaves by using the modified CTAB (Murray and Thompson 1980) and then preserved at $-20^{\circ} \mathrm{C}$ before genotyping. The PCR was performed using a 20 $\mu \mathrm{L}$ reaction mixture, which contains $2.0 \mu \mathrm{L}$ DNA template $(50 \mathrm{ng} / \mu \mathrm{L}), 2.0 \mu \mathrm{L}$ PCR buffer $(10 \times), 2.0 \mu \mathrm{L} \mathrm{Mg}{ }^{2+}(25 \mathrm{mM})$, $1.5 \mu \mathrm{L}$ forward and reverse primer $(1 \mu \mathrm{M}), 0.2 \mu \mathrm{L}$ dNTPs $(10 \mathrm{mM})$, and $1 \mathrm{U}$ Taq DNA polymerase. PCR reactions were performed as follow: $94^{\circ} \mathrm{C}$ for $3 \mathrm{~min}, 32$ cycles of $94^{\circ} \mathrm{C}$ for $30 \mathrm{~s}, 55^{\circ} \mathrm{C}$ for $30 \mathrm{~s}$, and $1 \mathrm{~min}$ at $72^{\circ} \mathrm{C}$; and a final extension at $72^{\circ} \mathrm{C}$ for $10 \mathrm{~min}$. PCR products were genotyped using $6 \%$ polyacrylamide gel electrophoresis.

\section{Gene cloning}

The primer sequences used for candidate gene cloning were listed in Supplementary Table S1. The PCR amplicons of candidate genes were ligated to the PMD-19T cloning vector (Takara, Tokyo, Japan). At least three randomly selected positive colonies for each amplicon were sequenced and assembled. Nucleotides and amino acid sequences were aligned using DNAMAN (version 9).

\section{Expression analysis}

For comparative expression analysis, the mixed samples comprised of the flower buds (white arrow 1), main stem (white arrow 2) close to the first branching point and the pedicel (white arrow 3) were excised as a whole at four developmental stages including S1 to S4 (Fig. 1), respectively, for RNA isolation. To characterize the expression profile of Capana12g000958, the flower bud/fruit and pedicel samples at seven developmental stages (S1 to S7, as described in Fig. 5) were excised separately from the BB3, Chiltepin, and BB3×Chiltepin $\left(F_{1}\right)$, respectively, for RNA isolation. Every sample was collected in three biological replicates, wrapped in tin foil, frozen directly in liquid nitrogen, and then stored at $-80^{\circ} \mathrm{C}$ for subsequent experiments.

Total RNA was isolated by using the Eastep® Super Total RNA Extraction Kit (LS1040; Promega, Madison, America) following the manufacturer's instructions. First-strand cDNA was synthesized by using a cDNA synthesis kit (Takara, Tokyo, Japan). qRT-PCR was performed in triplicate by using SYBR Green PCR master mix (Takara, Tokyo, Japan) on a BioRad CFX96 system (Bio-Rad, CA, USA). The primer sequences of the candidate genes and Ca-Actin were listed in Supplementary Table S2. PCR was performed with an initial denaturation step set at $94^{\circ} \mathrm{C}$ for 3 min, followed by 39 cycles of denaturation and annealing at $94^{\circ} \mathrm{C}$ for $10 \mathrm{~s}$ and $55^{\circ} \mathrm{C}$ for $30 \mathrm{~s}$, respectively. The relative expression level was analyzed using the $2^{-\Delta \Delta C T}$ method (Livak and Schmittgen 2001). All reactions were performed in triplicate with three biological replicates for each sample.

\section{Results}

\section{Dynamic change and inheritance of fruit orientation}

Through continuous observation, we found that the orientation of flower buds displayed no difference at the stage S1 when corolla was tightly wrapped by the calyx between BB3 and Chiltepin (Fig. 1). From stage S3 to S7, BB3 and Chiltepin exhibited an obvious difference in pedicel or fruit orientation with the significant change that occurred from the stage S2 to S3 (Fig. 1). After stage S3, all pedicels and fruits from the BB3 plants displayed vertical pendant phenotype, while that of the Chiltepin plants exhibited erect orientation, and all of the BB3 $\times$ Chiltepin $\left(\mathrm{F}_{1}\right)$ plants showed a lateral pendant (LP) pedicel/fruit orientation phenotype (Fig. 1). Among the $B C_{1} F_{1}$ population $(n=225)$, 111 plants showed a vertical pendant (VP) fruit orientation similar to that of BB3, and 114 presented the lateral 
pendant (LP) fruit orientation as with that of the BB3 $\times$ Chiltepin $\left(\mathrm{F}_{1}\right)$. Chi-square tests revealed that the observed segregation in the $\mathrm{BC}_{1} \mathrm{~F}_{1}$ population fitted the expected ratio $1: 1(\chi 2=0.04, P>0.05)$. These findings indicated that variations in fruit orientation between BB3 and Chiltepin were controlled by a single semi-dominant gene.

\section{Verification of the major QTL Up12.1}

Fourteen polymorphic InDel markers (Supplementary Table S3) between BB3 and Chiltepin were developed within the Up12. 1 interval and then were used to genotype the $225 \mathrm{BC}_{1} \mathrm{~F}_{1}$ individuals. Linkage mapping demonstrated that all markers had a tight linkage less than $2.34 \mathrm{cM}$ with fruit orientation (Fig. 2a). Out of the 14 polymorphic markers, seven markers including the FO-551, FO-818, FO-771, FO-704, FO-78, FO-616, and FO-508 were found to be cosegregated with the up locus among the $225 \mathrm{BC}_{1} \mathrm{~F}_{1}$ individuals (Fig. 2a). This finding suggested that Up 12.1 was also responsible for variation in fruit orientation between BB3 and Chiltepin. The up locus was therefore delimited within the interval between marker FO-572 and FO-277 with a physical length of 2.43 Mb (Fig. 2a).

\section{Fine mapping of the up locus}

A large $B C_{1} F_{2}$ population consisting of 1,827 individuals was developed to screen recombinant events by using the markers FO-572, FO-277, as well as F0-616 (Fig. 2b). A total of 11 recombinant plants were identified between FO572 and F0-277, and eight out of them underwent recombination between the F0-572 and F0-616 (Fig. 2c). Additional nine polymorphic InDel markers (Supplementary Table S4) were developed within the interval between FO572 and F0-277 and then were used for genotyping of the 11 recombinants. Results showed that three markers, namely F0-771, FO-676 and F0-946, were found to be co-segregated with the fruit orientation (Fig. 3). As a result, the up locus could be eventually localized between the markers FO-818 and F0-951 with a physical distance of $~ 169.51$ kb (Fig. 2b and Fig. 3).

\section{Sequence comparisons of the candidate genes}

A total of seven protein-coding genes were annotated within the fine-mapping interval of the up locus (Table 1). Of which, Capana12g000958 was highly orthologous (Bit score $=614$ and E-value $=0$ ) to the Arabidopsis thaliana developmentally regulated G-protein 2 (DRG2) gene (Supplementary Figure S1). Capana12g000960 and Capana12g000966 showed a high degree of sequence similarity (Identity $=99.70 \%$ ) to each other and both of them encode ELF4-LIKE3 protein (Supplementary Figure S2). The rest of the four candidate genes including Capana12g000959, Capana12g000962, Capana12g000964 and Capana12g000965 had no significant (E-value > 1e5) homologous genes in the public database to date (Table 1). 
Table 1

List of seven candidate genes for the pepper up locus.

\begin{tabular}{|c|c|c|c|c|c|c|c|}
\hline Gene & Start & End & $\begin{array}{l}\text { Gene } \\
\text { symbol }\end{array}$ & $\begin{array}{l}\text { Homologous } \\
\text { species }\end{array}$ & $\begin{array}{l}\text { Homologous } \\
\text { protein }\end{array}$ & $\begin{array}{l}\mathrm{E}- \\
\text { value }\end{array}$ & $\begin{array}{l}\text { Bit } \\
\text { score }\end{array}$ \\
\hline Capana12g000958 & $37,644,791$ & $37,650,731$ & $D R G 2$ & $\begin{array}{l}\text { Arabidopsis } \\
\text { thaliana }\end{array}$ & $\begin{array}{l}\text { Developmentally } \\
\text { regulated G- } \\
\text { protein } 2\end{array}$ & 0 & 614 \\
\hline Capana12g000959 & $37,683,574$ & $37,688,329$ & 1 & 1 & 1 & & \\
\hline Capana12g000960 & $37,689,586$ & $37,689,918$ & EFL3 & $\begin{array}{l}\text { Arabidopsis } \\
\text { thaliana }\end{array}$ & $\begin{array}{l}\text { Protein ELF4- } \\
\text { LIKE } 3\end{array}$ & $\begin{array}{l}1.6 \mathrm{E}- \\
38\end{array}$ & 128 \\
\hline Capana12g000962 & $37,733,635$ & $37,734,657$ & 1 & 1 & & & \\
\hline Capana12g000964 & $37,739,818$ & $37,740,560$ & 1 & 1 & 1 & & \\
\hline Capana 12g000965 & $37,783,070$ & $37,785,471$ & 1 & & & & \\
\hline Capana12g000966 & 37786745 & 37787077 & EFL3 & $\begin{array}{l}\text { Arabidopsis } \\
\text { thaliana }\end{array}$ & $\begin{array}{l}\text { Protein ELF4- } \\
\text { LIKE } 3\end{array}$ & $\begin{array}{l}1.6 \mathrm{E}- \\
38\end{array}$ & 127 \\
\hline
\end{tabular}

We tried to clone and compare the full cDNA sequences of all the above-mentioned candidate genes between BB3 and Chiltepin. However, we could not obtain any amplification product for Capana12g000962, Capana12g000964 and Capana12g000965, using all the tested cDNA samples from roots, stems, leaves, flowers and fruits as template. We checked their expression in another 46 pepper transcriptome data and found they almost were not expressed (Supplementary Figure S3). As for the other four genes, there was no variation for coding sequences of Capana12g000958 (Supplementary Figure S4), Capana12g000960 and Capana12g000966 (Supplementary Figure S2), but two non-synonymous SNPs were found in that of Capana12g000959 (Supplementary Figure S5) between BB3 and Chiltepin.

\section{Comparative expression analysis of the candidate genes}

To further determine which candidate may be responsible for the differentiation of fruit orientation, we compared the expression levels of Capana12g000958, Capana12g000959 and Capana12g000960/66 in the mixed samples of flower buds, main stem close to the first branching point and pedicel from stage S1 to S4 among the BB3, Chiltepin and BB3 $\times$ Chiltepin $\left(\mathrm{F}_{1}\right)$. The results showed that Capana12g000958's expression was gradually increased from stage $\mathrm{S} 1$ to $\mathrm{S} 4$ in BB3, Chiltepin and BB3×Chiltepin $\left(\mathrm{F}_{1}\right)$. Notably, Capana12g000958 displayed significantly difference between BB3 and Chiltepin at all four stages (Fig. 4a). The expression levels of Capana12g000959 (Fig. 4b) and Capana12g000960/Capana12g000966 (Fig. 4c) did not change much from stage S1 to S4 in BB3, Chiltepin and BB3×Chiltepin (F1). In addition, there was no obvious expression difference for Capana12g000959, Capana12g000960/Capana12g000966 at all stages between BB3 and Chiltepin with the exception of that at stage S4 for Capana12g000959 (Fig. 4b and 4c).

\section{Expression profile of Capana12g000958 in pepper}

Sequence and expression comparisons collectively indicated that Capana12g000958 was the most likely candidate gene for up. As a result, we conducted an elaborate sample collection to characterize the expression profile of 
Capana12g000958 in pepper. Results showed that the expression level of Capana12g000958 represented an upward tendency from stage S1 to S4 in the flowers (Fig. 5a), which was similar to that in the mixed samples (Fig. 4a), and then it maintained a constant low expression level from stage S5 to S7 of fruits in BB3, Chiltepin and BB3×Chiltepin $\left(F_{1}\right)$ (Fig. 5a). Furthermore, Capana12g000958 was expressed significantly higher in BB3 than that in both Chiltepin and BB3 $\times$ Chiltepin $\left(F_{1}\right)$ at stage S4 in the flower (Fig. 5a). With respect to the Capana12g000958's expression in the pedicle, a trend of rising from stage S1 to S4 and falling from stage S5 to S7 was observed in BB3, Chiltepin and BB3 $\times$ Chiltepin $\left(\mathrm{F}_{1}\right)$. Intriguingly, the expression of Capana12g000958 in BB3 was significantly higher than that in both Chiltepin and BB3×Chiltepin $\left(F_{1}\right)$ after stage 22 (Fig. 5b). In addition, tissue-specific expression analysis showed Capana12g000958 expression was higher in the flower-related tissues including receptacles, anthers, and petals than that in the root, stem and leave (Supplementary Figure S6).

\section{Discussion}

Fruit orientation is an important horticultural trait for pepper because it has significant impact on pollination efficiency, yield, and harvesting approaches (Lee et al. 2008; Wang et al. 2014a). Herein, in order to avoid the deficiency of sterility and incompatibility of the interspecific cross between BA3 (C. annuum) and YNXML ( $C$. frutescens) (Cheng et al. 2016a), we turned to use the intraspecific population derived from the cross of BB3 ( $C$. annuum) and its wild progenitor Chiltepin (C. annuum var. glabriusculum) to fine map the up locus. Linkage mapping demonstrated that the major QTL Up12.1 was also responsible for fruit orientation variation in the BB3 $\times(B B 3 \times$ Chiltepin) population (Fig. 2a). The result of this study adds new evidence to our previous deduction that the Up12.1 could be the same QTL as FP-12.2, which was also identified in an intraspecific RIL population of $C$. annuum (Han et al. 2016), indicating that the origin of the up gene should occur before the species differentiation between $C$. annuum and $C$. frutescens.

The completion of pepper genome sequencing has markedly accelerated the mining of target genes through forward genetics approach although it's still a draft version (Kim et al. 2014; Qin et al. 2014; Hulse-Kemp et al. 2018). In this study, there is an inconsistence between the genetic and physical order within the preliminary mapping interval from marker FO-508 to FO-620 (Fig. 2a, 2b and Supplementary Table S3). This entire interval was found to be located on the scaffold445 (Fig. 2) whose orientation has not yet been defined because it was anchored only by one SNP (Cheng et al. 2020). Thus, in addition to the FO-572 and FO-277, we also used the FO-616 to screen recombinants from the large population. The recombinant events of FO-616, FO-277 and FO-508 further confirmed the existence of scaffold inversion (Fig. 2b). Nevertheless, because the co-segregation region was located on another scaffold (scaffold1796), this inversion should make no difference to the final fine mapping (Fig. 2). Based on the analysis of recombinants identified from the large population, the candidate interval for up locus was narrowed into a region between FO-818 and FO-951 with a physical length of $169.51 \mathrm{~kb}$ (Fig. 2). To our knowledge, this is the first time such a precise interval has been reported for the up locus to date.

Seven protein-coding genes were annotated in this fine mapping interval (Table 1), however, none of them showed homology to the known regulators governing alterations of pedicel orientation (Cheng et al. 2016a), indicating that the pepper up gene is possibly a new member that participated in the pedicel orientation regulation pathway. Further expression analysis showed that three out of the seven candidates, Capana12g000962, Capana12g000964 and Capana12g000965, were very likely to be pseudogenes because they were not expressed in all the tested samples from this study as well as in another 46 pepper samples from different sources (Supplementary Figure S3). For Capana12g000960/66, there was no difference either in the expression level or sequence comparison between BB3 and Chiltepin (Fig. 4c and Supplementary Figure S2). Sequence comparison between BB3 and Chiltepin revealed that 
there were two non-synonymous SNPs in the coding sequences of Capana12g000959, but they do not exist in the Zunla-1 and YNXML (Supplementary Figure S5), both of which exhibit erect fruit orientation. With regard to Capana12g000958, we found its spatial and temporal differential expression between parental lines in the pedicle was highly corresponding to the fruit orientation change (Fig. 1 and Fig. 5b). Furthermore, a SNP located in the promoter region was in line with the fruit orientation phenotype of eight pepper breeding lines (958pro_SNP4_37651506, Supplementary Figure S7) despite there was no difference in the coding region. Taken together, we suggested that Capana12g000958 was the strongest candidate gene for up.

Capana 12 g000958 shared 88\% of amino acid sequence similarity with the Arabidopsis thaliana DRG2 (Supplementary Figure S1), which belongs to the highly conserved GTP-binding protein (also known as G protein) family that found in archaea, plants, fungi and animals, indicating their pivotal roles in fundamental pathways (Ma 1994; O'Connell et al. 2009). Plant G-proteins have been implicated in regulation of almost every aspect of growth, development, hormonal perception, response to biotic and abiotic stresses (Assmann 2002; Pandey and Vijayakumar 2018). Intriguingly, several G proteins were identified as vital regulators of plant organ growth direction. For example, in Arabidopsis, the $A G B 1$ encoding the $\beta$-subunit of the $\mathrm{G}$ protein negatively regulates auxin-induced cell division and affects the hook angle (Ullah et al. 2003; Chakravorty et al. 2012). Rop2 GTPase, a kind of small G protein, can regulate the early phase of organogenesis's directional cell expansion (Fu et al. 2002; Jones et al. 2002). A complex, composing of ROP GTPases, its activators and effectors, and AGC1.5 subfamily kinases can regulate the polar dynamic distribution of apical growth (Li et al. 2020). In rice, the Dwarf 1 and DEP1 encoding the a-subunit and $\gamma^{-}$ subunit of heterotrimeric $\mathrm{G}$ protein, respectively, can regulate the panicle architecture (Ashikari et al. 1999; Huang et al. 2009). At the post-transcriptional level, small Ras GTP-binding protein was found to be related to fruit bending in cucumber (Wang et al. 2014b). All above evidences prompt speculation that Capana12g000958 might be a signaling molecule involved in the dynamic control of fruit orientation in pepper. Further investigation would be necessary to analyze the function of Capana12g000958 in future.

\section{Declarations}

\section{Acknowledgments}

This research was supported by the National Natural Science Foundation of China (31701921, 31672162), Guangdong Basic and Applied Basic Research Foundation (2019A1515011784), and Guangzhou Science and Technology Plan Projects (201704020019).

\section{Author contribution statement}

FH, JWC, and KLH conceived and designed all experiments; FH, JCD, JZ performed the experiments; FH and JWC analyzed the data; FH, JWC and KLH wrote the manuscript; All authors read and approved the final manuscript.

\section{Compliance with ethical standards}

\section{Conflict of interest}

Authors declare that they have no conflict of interest. 


\section{Ethical statement}

Authors declare that this study complies with the current laws of China.

\section{References}

1. Ashikari M, Wu J, Yano M, et al (1999) Rice gibberellin-insensitive dwarf mutant gene Dwarf 1 encodes the asubunit of GTP-binding protein. Proc Natl Acad Sci U S A 96:10284-10289.

https://doi.org/10.1073/pnas.96.18.10284

2. Assmann SM (2002) Heterotrimeric and unconventional GTP binding proteins in plant cell signaling. Plant Cell 14:355-373. https://doi.org/10.1105/tpc.001792

3. Castillo-Sánchez LE, Jiménez-Osornio JJ, Delgado-Herrera MA (2012) Actividad biolÓgica in vitro del extracto de capsicum chinense jacq contra bemisia tabaci genn. Rev Chapingo, Ser Hortic 18:345-356. https://doi.org/10.5154/r.rchsh.2011.04.016

4. Chakravorty D, Trusov Y, Botella JR (2012) Site-directed mutagenesis of the Arabidopsis heterotrimeric G protein $\beta$ subunit suggests divergent mechanisms of effector activation between plant and animal $G$ proteins. Planta 235:615-627. https://doi.org/10.1007/s00425-011-1526-5

5. Cheng J, Chen Y, Hu Y, et al (2020) Fine mapping of restorer-of-fertility gene based on high-density genetic mapping and collinearity analysis in pepper (Capsicum annuum L.). Theor Appl Genet 133:889-902. https://doi.org/10.1007/s00122-019-03513-y

6. Cheng J, Qin C, Tang X, et al (2016a) Development of a SNP array and its application to genetic mapping and diversity assessment in pepper (Capsicum spp.). Sci Rep 6:33293. https://doi.org/10.1038/srep33293

7. Cheng J, Zhao Z, Li B, et al (2016b) A comprehensive characterization of simple sequence repeats in pepper genomes provides valuable resources for marker development in Capsicum. Sci Rep 6:18919. https://doi.org/10.1038/srep18919

8. Douglas SJ, Chuck G, Dengler RE, et al (2002) KNAT1 and ERECTA regulate inflorescence architecture in Arabidopsis. Plant Cell 14:547-558. https://doi.org/10.1105/tpc.010391

9. Fu Y, Li H, Yang Z (2002) The ROP2 GTPase controls the formation of cortical fine F-actin and the early phase of directional cell expansion during arabidopsis organogenesis. Plant Cell 14:777-794. https://doi.org/10.1105/tpc.001537

10. Han K, Jeong HJ, Yang HB, et al (2016) An ultra-high-density bin map facilitates high-throughput QTL mapping of horticultural traits in pepper (Capsicum annuum). DNA Res 23:81-91.

https://doi.org/10.1093/dnares/dsv038

11. Hernández-Ortega M, Ortiz-Moreno A, Hernández-Navarro MD, et al (2012) Antioxidant, antinociceptive, and antiinflammatory effects of carotenoids extracted from dried pepper (Capsicum annuum L.). J Biomed Biotechnol 2012:1-10. https://doi.org/10.1155/2012/524019

12. Huang X, Qian Q, Liu Z, et al (2009) Natural variation at the DEP1 locus enhances grain yield in rice. Nat Genet 41:494-497. https://doi.org/10.1038/ng.352

13. Hulse-Kemp AM, Maheshwari S, Stoffel K, et al (2018) Reference quality assembly of the 3.5-Gb genome of Capsicum annuum from a single linked-read library. Hortic Res. https://doi.org/10.1038/s41438-017-0011-0

14. Jones MA, Shen JJ, Fu Y, et al (2002) The Arabidopsis Rop2 GTPase is a positive regulator of both root hair initiation and tip growth. Plant Cell 14:763-776. https://doi.org/10.1105/tpc.010359 
15. Kim S, Park M, Yeom SI, et al (2014) Genome sequence of the hot pepper provides insights into the evolution of pungency in Capsicum species. Nat Genet 46:270-278. https://doi.org/10.1038/ng.2877

16. Lee HR, Cho MC, Kim HJ, et al (2008) Marker development for erect versus pendant-orientated fruit in Capsicum annuum L. Mol Cells 26:548-553. https://doi.org/10.1080/19768354.2008.9647187

17. Li E, Zhang Y-L, Shi X, et al (2020) A positive feedback circuit for ROP-mediated polar growth. Mol Plant 108947. https://doi.org/10.1016/j.molp.2020.11.017

18. Li Y, Pi L, Huang H, Xu L (2012) ATH1 and KNAT2 proteins act together in regulation of plant inflorescence architecture. J Exp Bot 63:1423-1433. https://doi.org/10.1093/jxb/err376

19. Lin D, Xiang Y, Xian Z, Li Z (2016) Ectopic expression of SIAGO7 alters leaf pattern and inflorescence architecture and increases fruit yield in tomato. Physiol Plant 157:490-506. https://doi.org/10.1111/ppl.12425

20. Lippert LF, Bergh BO, Smith PG (1965) Gene list for the pepper. J Hered 56:30-34. https://doi.org/10.1093/oxfordjournals.jhered.a107366

21. Livak KJ, Schmittgen TD (2001) Analysis of relative gene expression data using real-time quantitative PCR and the $2^{-\triangle \triangle C T}$ method. Methods 25:402-408. https://doi.org/10.1006/meth.2001.1262

22. Ma H (1994) GTP-binding proteins in plants: new members of an old family. Plant Mol Biol. https://doi.org/10.1007/BF00016493

23. Murray MG, Thompson WF (1980) Rapid isolation of high molecular weight plant DNA. Nucleic Acids Res 8:4321-4326. https://doi.org/10.1093/nar/8.19.4321

24. O'Connell A, Robin G, Kobe B, Botella JR (2009) Biochemical characterization of Arabidopsis developmentally regulated G-proteins (DRGs). Protein Expr Purif 67:88-95. https://doi.org/10.1016/j.pep.2009.05.009

25. Pandey S, Vijayakumar A (2018) Emerging themes in heterotrimeric G-protein signaling in plants. Plant Sci. 270:292-300. https://doi.org/10.1016/j.plantsci.2018.03.001

26. Paran I, Van Der Knaap E (2007) Genetic and molecular regulation of fruit and plant domestication traits in tomato and pepper. J. Exp. Bot. 58:3841-3852. https://doi.org/10.1093/jxb/erm257

27. Qin C, Yu C, Shen Y, et al (2014) Whole-genome sequencing of cultivated and wild peppers provides insights into Capsicum domestication and specialization. Proc Natl Acad Sci U S A 111:5135-5140.

https://doi.org/10.1073/pnas.1400975111

28. Ragni L, Belles-Boix E, Günl M, Pautot V (2008) Interaction of KNAT6 and KNAT2 with Brevipedicellus and Pennywise in Arabidopsis inflorescences. Plant Cell 20:888-900. https://doi.org/10.1105/tpc.108.058230

29. Reilly CA, Crouch DJ, Yost GS, Fatah AA (2001) Determination of capsaicin, dihydrocapsaicin, and nonivamide in self-defense weapons by liquid chromatography-mass spectrometry and liquid chromatography-tandem mass spectrometry. J Chromatogr A 912:259-267. https://doi.org/10.1016/S0021-9673(01)00574-X

30. Roychoudhry S, Del Bianco M, Kieffer M, Kepinski S (2013) Auxin controls gravitropic setpoint angle in higher plant lateral branches. Curr Biol 23:1497-1504. https://doi.org/10.1016/j.cub.2013.06.034

31. Sun J, Xiao T, Nie J, et al (2019) Mapping and identification of CsUp, a gene encoding an auxilin-like protein, as a putative candidate gene for the upward-pedicel mutation (up) in cucumber. BMC Plant Biol 19:157.

https://doi.org/10.1186/s12870-019-1772-4

32. Ullah H, Chen JG, Temple B, et al (2003) The $\beta$-subunit of the arabidopsis G protein negatively regulates auxininduced cell division and affects multiple developmental processes. Plant Cell 15:393-409.

https://doi.org/10.1105/tpc.006148

Page 10/15 
33. Venglat SP, Dumonceaux T, Rozwadowski K, et al (2002) The homeobox gene brevipedicellus is a key regulator of inflorescence architecture in Arabidopsis. Proc Natl Acad Sci U S A 99:4730-4735.

https://doi.org/10.1073/pnas.072626099

34. Wang D, Chen X, Zhang Z, et al (2015) A MADS-box gene NtSVP regulates pedicel elongation by directly suppressing a KNAT1-like KNOX gene NtBPL in tobacco (Nicotiana tabacum L.). J Exp Bot 66:6233-6244. https://doi.org/10.1093/jxb/erv332

35. Wang H, Tie S, Yu D, et al (2014a) Change of floral orientation within an inflorescence affects pollinator behavior and pollination efficiency in a bee-pollinated plant, corydalis sheareri. PLoS One 9: e95381.

https://doi.org/10.1371/journal.pone.0095381

36. Wang LL, Zhang P, Qin ZW, Zhou XY (2014b) Proteomic analysis of fruit bending in cucumber (Cucumis sativus L.). J Integr Agric 13:963-974. https://doi.org/10.1016/S2095-3119(13)60406-2

37. Xu L, Xu Y, Dong A, et al (2003) Novel as 1 and as2 defects in leaf adaxial-abaxial polarity reveal the requirement for ASYMMETRIC LEAVES1 and 2 and ERECTA functions in specifying leaf adaxial identity. Development 130:4097-4107. https://doi.org/10.1242/dev.00622

38. Yamaguchi N, Suzuki M, Fukaki H, et al (2007) CRM1/BIG-mediated auxin action regulates Arabidopsis inflorescence development. Plant Cell Physiol 48:1275-1290. https://doi.org/10.1093/pcp/pcm094

39. Yamaguchi N, Yamaguchi A, Abe M, et al (2012) LEAFY controls Arabidopsis pedicel length and orientation by affecting adaxial-abaxial cell fate. Plant J 69:844-856. https://doi.org/10.1111/j.1365-313X.2011.04836.x

\section{Figures}

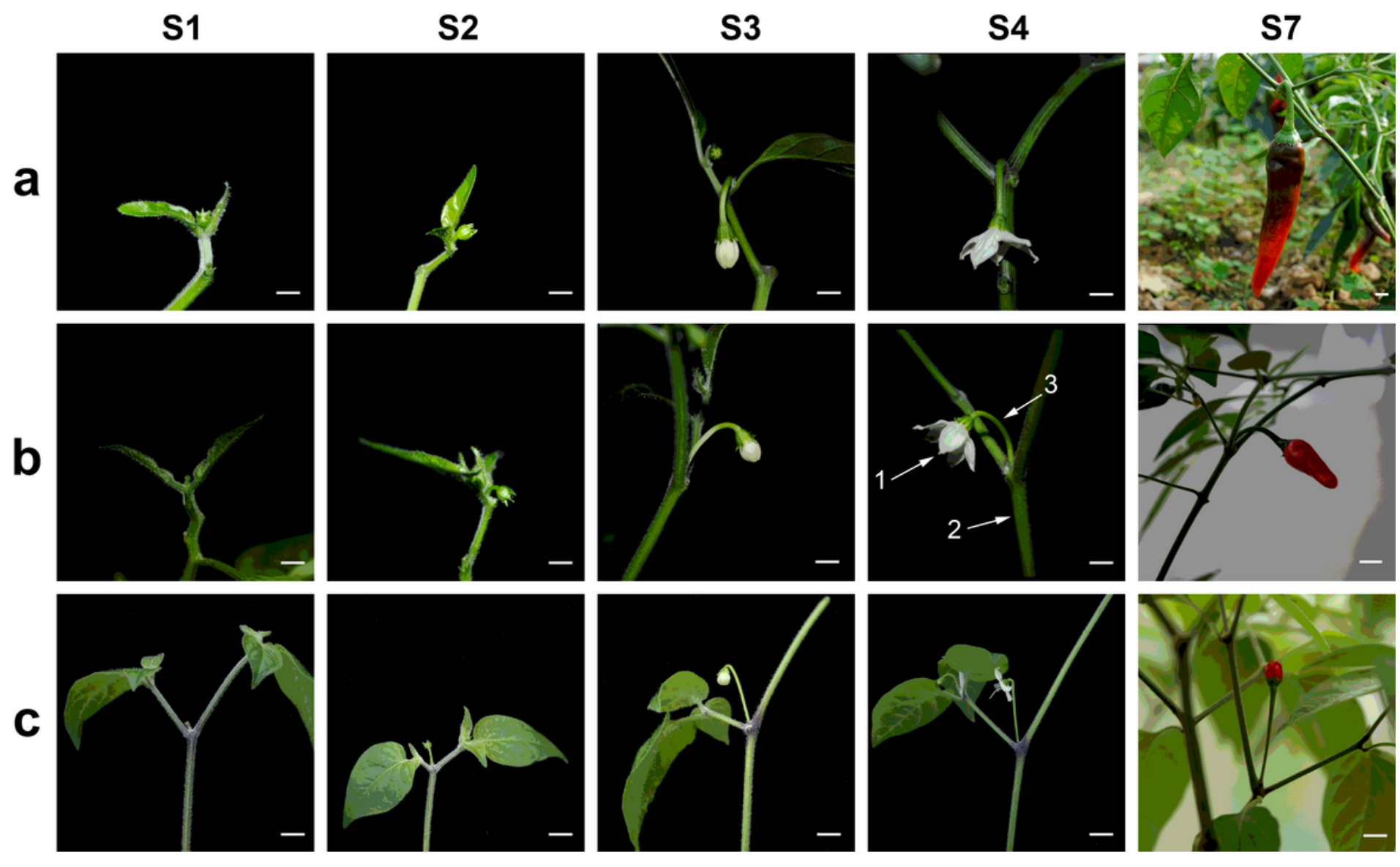

Figure 1 
Dynamic development of fruit orientation in BB3, F1 and Chiltepin (a) BB3 with vertical pendant (VP) flower and fruit. (b) F1 with lateral pendant (LP) flower and fruit. (c) Chiltepin with erect (E) flower and fruit. S1, S2, S3, S4 and S7 represent different stages of flower buds (S1: the corolla is wrapped by calyx. S2: the calyx split slightly and the flower stalk bends. S3: the flower will bloom the next day. S4: fully opened flower) and mature fruit (S7: 55 days after flowing), respectively. 1, 2 and 3 represent the sampling site of the sessile flowers, pedicel and main stem close to the first branching point, respectively

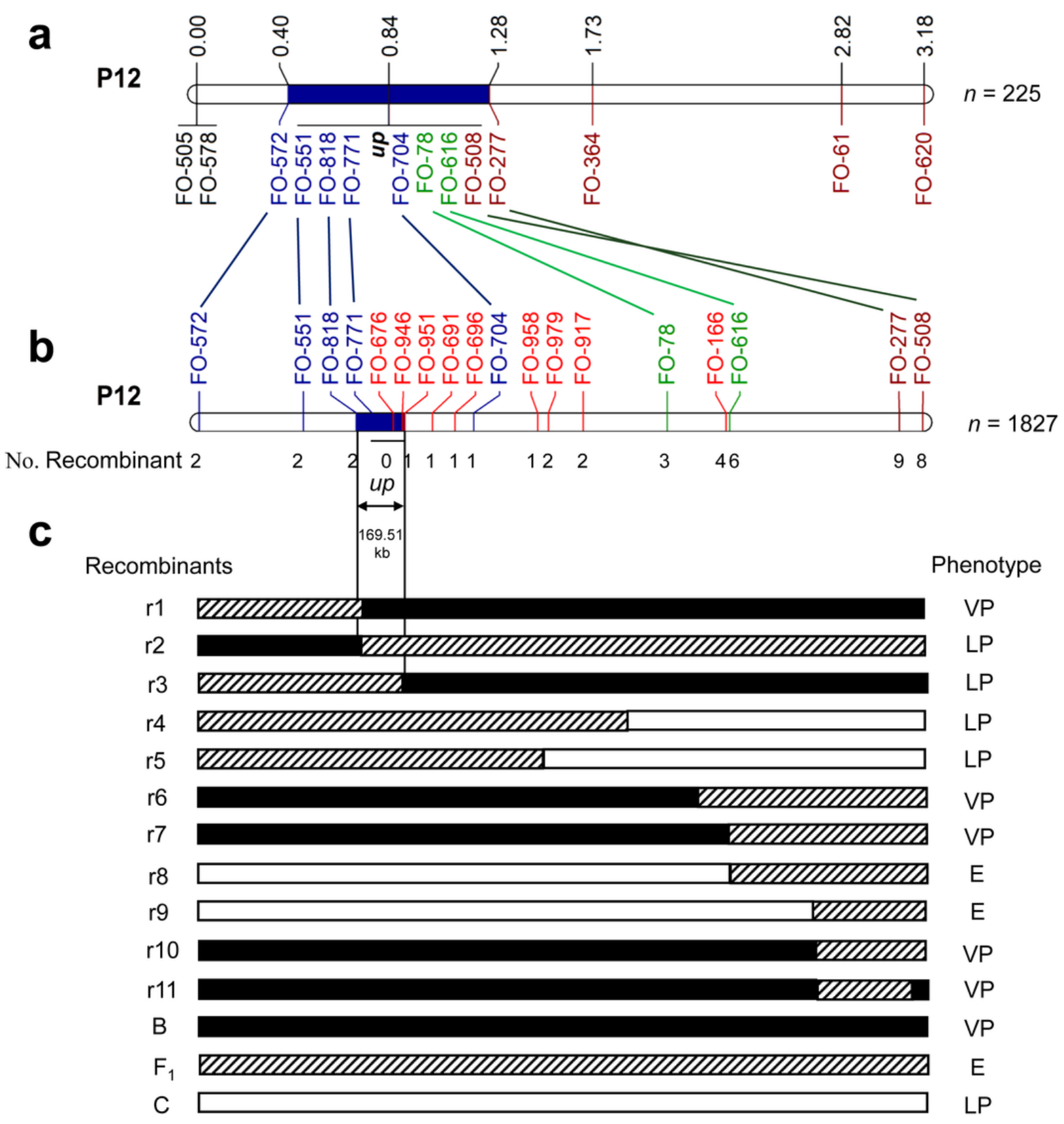

Figure 2

Fine-mapping of the up gene (a) genetic map of the preliminary mapping interval from the BC1F1 (BB3 $\times$ Chiltepin) population. The dark blue segment indicates the candidate region of the up gene. The solid line represents the collinearity analysis of physical and genetic maps. The black, blue, green and brown labeled markers were anchored 
to the Scaffold5893, Scaffold1796, Scaffold772 and Scaffold445, respectively. (b) The up falls within the interval between FO-818 and FO-951 in the fine map generated from analysis of 1827 BC1F2 segregants. The red markers are newly developed for fine mapping. The numbers below the line are the recombinants. (c) Graphical genotypes of BC1F2 recombinants and their corresponding fruit orientation phenotypes. The genetic composition of each recombinant category is shown in different colors. Black, white, and grid rectangles denote homozygous BB3 genotype (VP, vertical pendant), homozygous Chiltepin genotype (E, erect), and heterozygous F1 genotype (LP, lateral pendant), respectively. r1-r11 represents recombinants

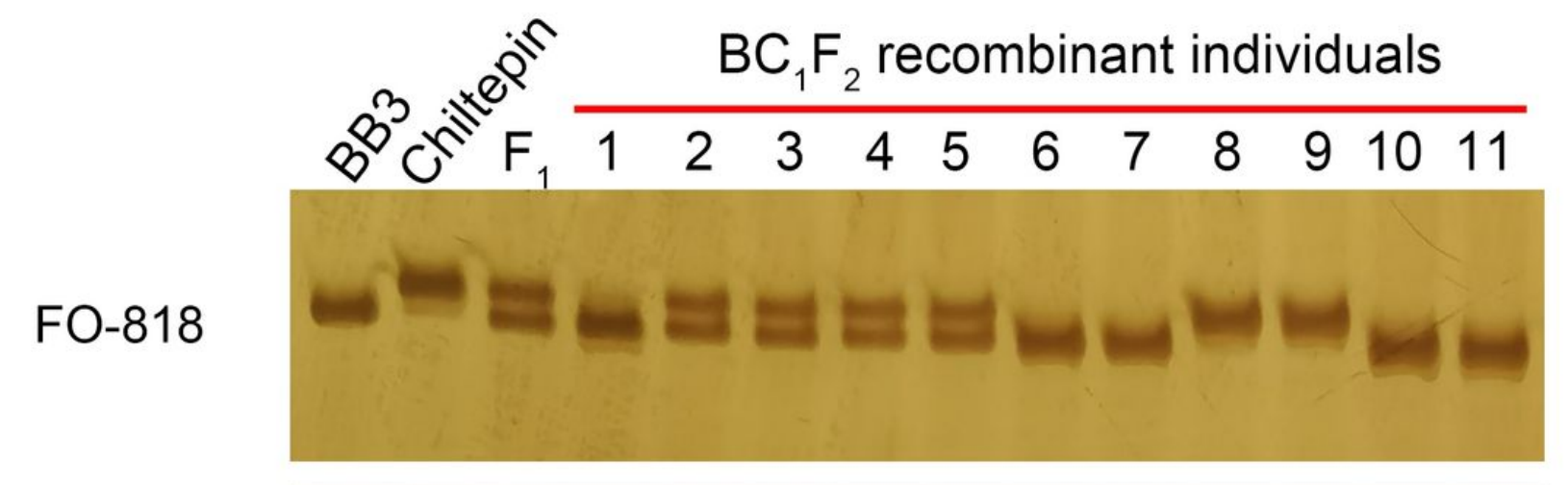

FO-771

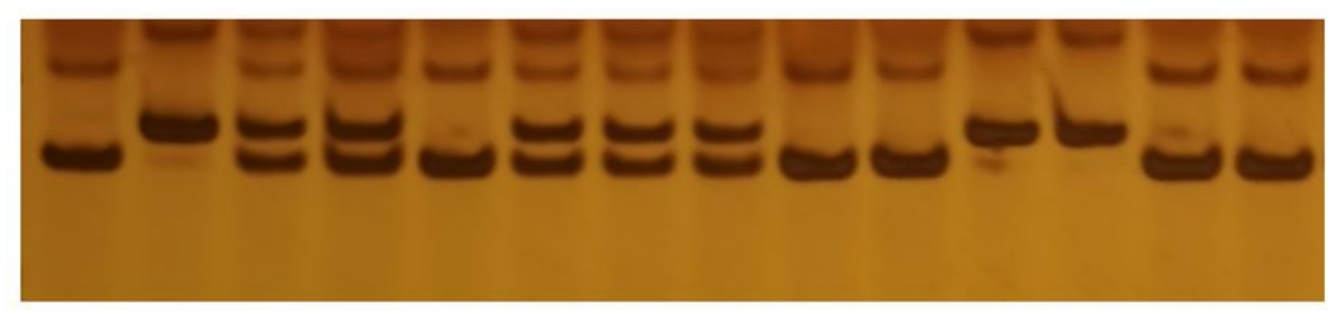

FO-676

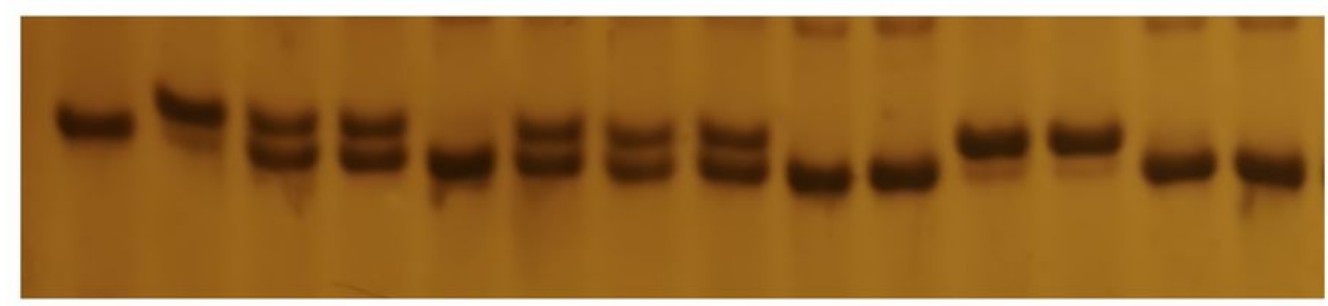

FO-946

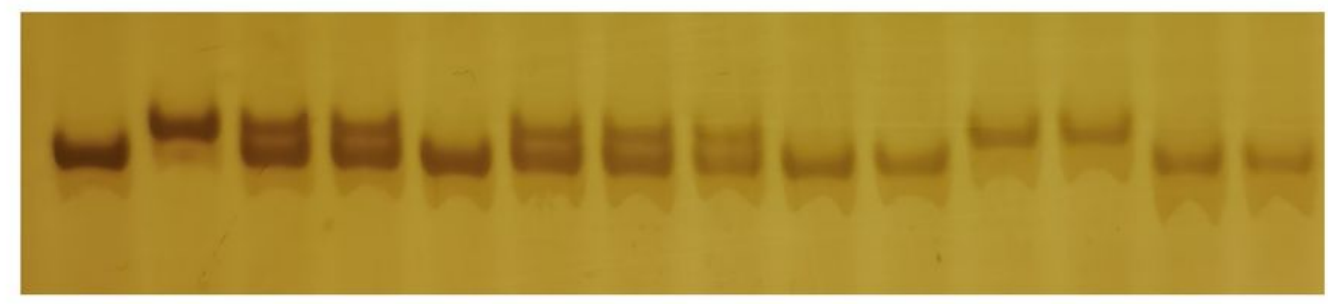

FO-951

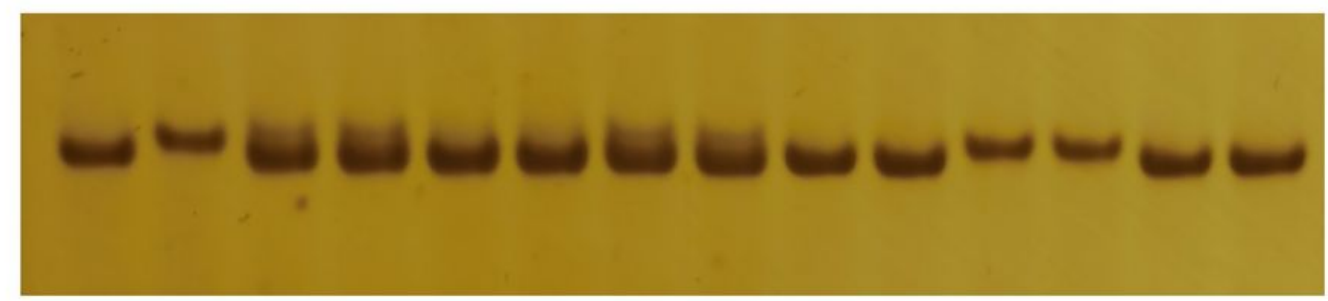

\section{Fruit orientation VP E LP LP VP LP LP LP VP VP E E VP VP}

\section{Figure 3}

Genotyping results of several markers located in the fine mapping interval from the $11 \mathrm{BC} 1 \mathrm{~F} 2$ recombinants E, VP anf LP represent the erect, vertical pendant and lateral pendant fruit orientation phenotypes, respectively. S1 S4 
represent different stages of flower buds. S5 S7 represent different development stages of fruit (33, 44 and 55 days after flowing), respectively
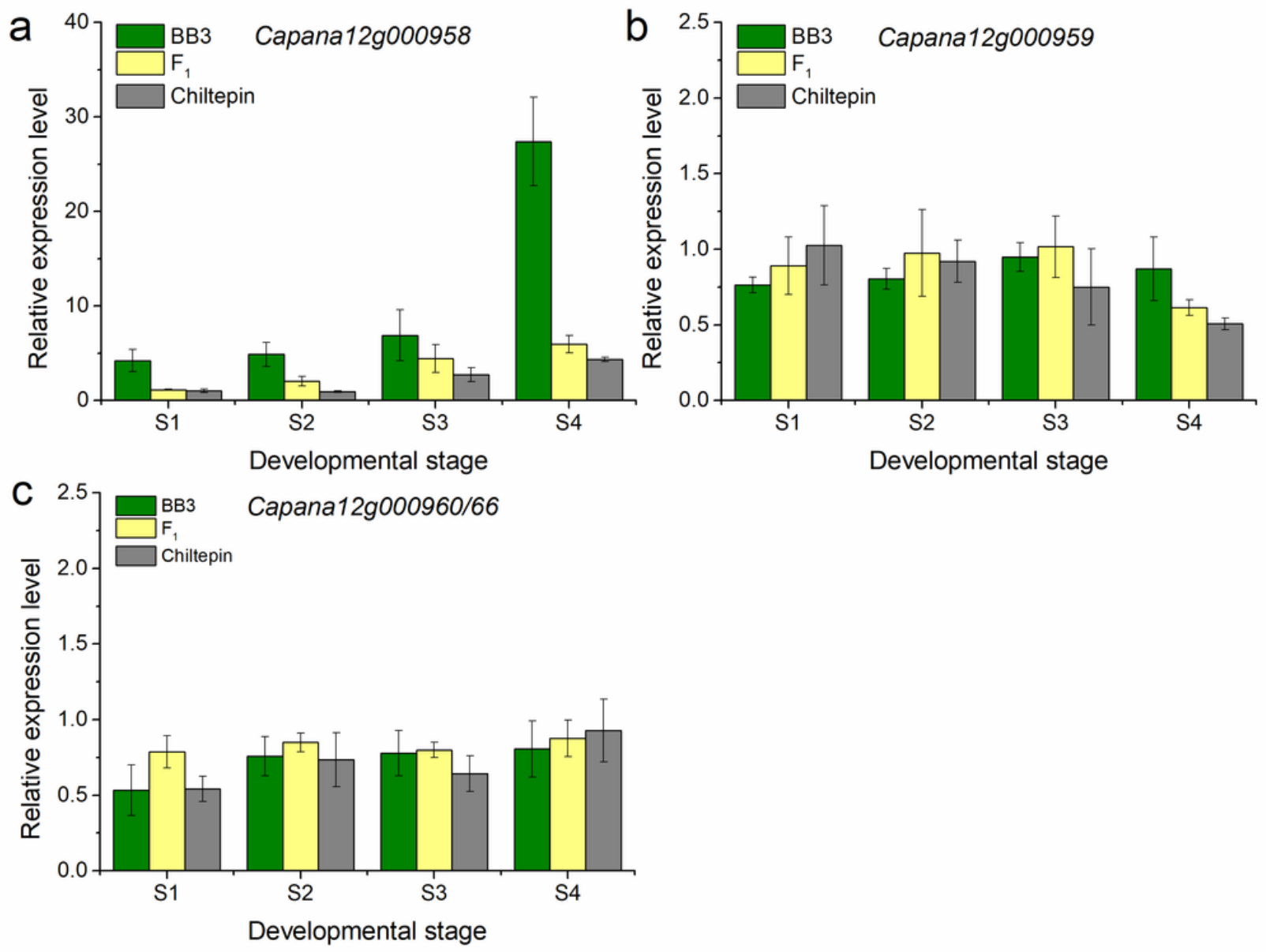

\section{Figure 4}

Relative expression of the candidate genes in the mixed samples (stems, pedicels and flower buds) of BB3, F1 and Chiltepin 

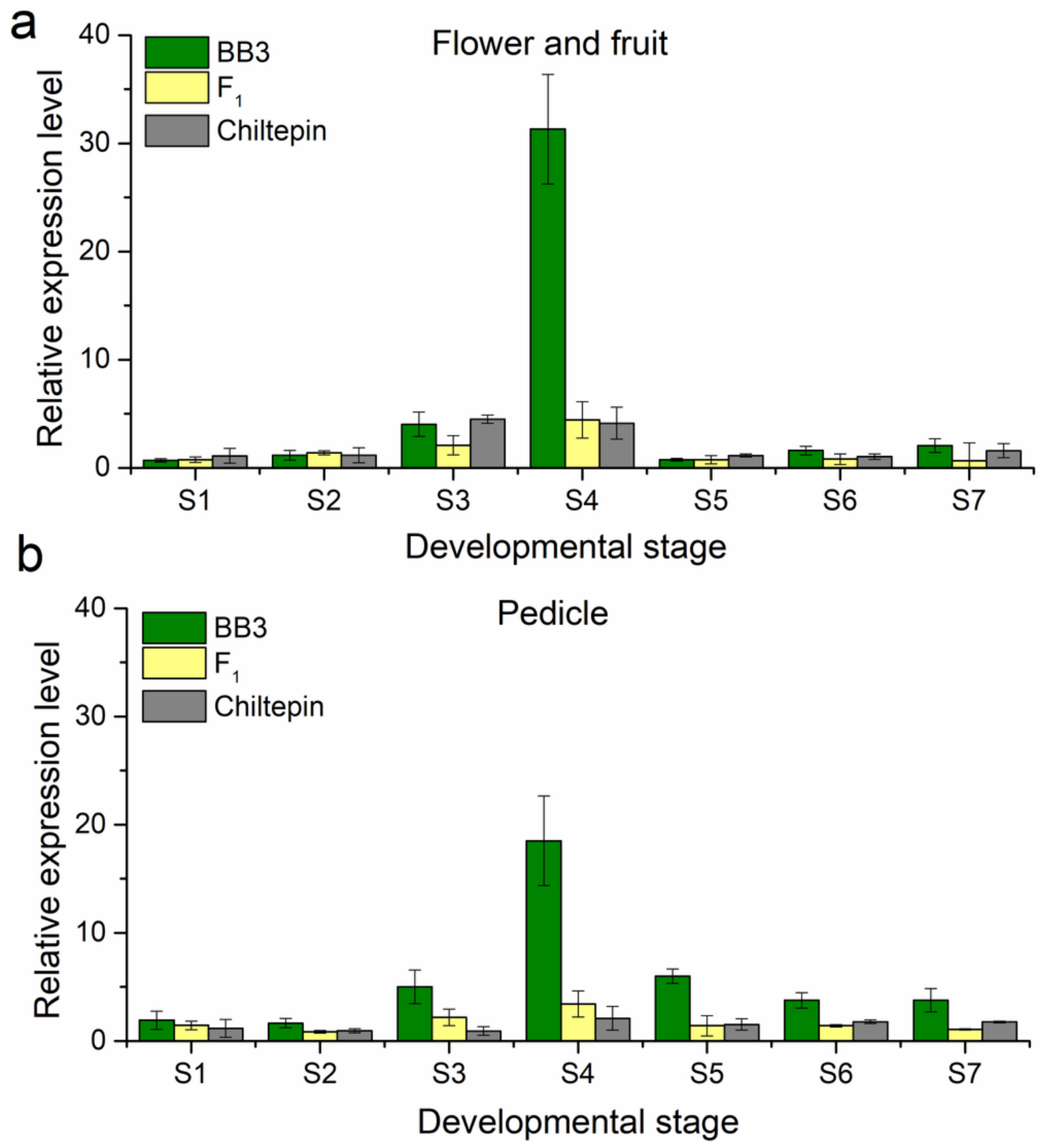

Figure 5

Expression profile of Capana12g000958 based on qPCR analysis in BB3,Chiltepin and BB3×Chiltepin (F1). (a) The expression level of Capana12g000958 in the flowers from stage S1 to S4, and in fruits from S5 to S7. (b) The expression level of Capana12g000958 in the in pedicles from stage S1 to S7

\section{Supplementary Files}

This is a list of supplementary files associated with this preprint. Click to download.

- Supplementary.docx 